\title{
Trauma Surgery \& Acute Care Open \\ Improving survival after an emergency resuscitative thoracotomy: a 5-year review of the Trauma Quality Improvement Program
}

\author{
Bellal Joseph, ${ }^{1}$ Muhammad Khan, ${ }^{1}$ Faisal Jehan, ${ }^{1}$ Rifat Latifi, ${ }^{2}$ Peter Rhee ${ }^{3}$
}

'Division of Trauma, Critical Care, Emergency Surgery, and Burns, Department of Surgery, University of Arizona, Tucson, Arizona, USA

2Department of General Surgery, Westchester Medical Center Valhalla, New York, USA 'Division of Trauma and Acute Care Surgery, Grady Memorial Hospital, Atlanta, Georgia, USA

\section{Correspondence to} Dr Bellal Joseph, Division of Trauma, Critical Care, And Emergency Surgery, Department of Surgery, University of Arizona, Tucson, AZ 85721, USA; bjoseph@surgery.arizona.edu

Received 23 June 2018 Revised 13 August 2018 Accepted 21 August 2018

(c) Author(s) (or their employer(s)) 2018. Re-use permitted under CC BY-NC. No commercial re-use. See rights and permissions. Published by BMJ.

To cite: Joseph B, Khan M, Jehan F, et al. Trauma Surg Acute Care Open

2018:3:e000201.

\section{ABSTRACT}

Background Advancement in trauma care has led to the evolution of emergency resuscitative thoracotomy (ERT) for the revival of trauma patients. We now have more precise understanding of selecting suitable patients for achieving optimal outcomes. The aim of our study was to analyze the utilization and survival trends during the past 5 years, as well as factors that influence survival after ERT.

Methods A 5-year (2010-2014) analysis of all trauma patients $\geq 18$ years who underwent ERT in the American College of Surgeons Trauma Quality Improvement Program. Outcome measures were utilization rates and survival trends after ERT during the 5-year period. Regression analysis was performed.

Results 2229 patients underwent ERT, mean age was $37 \pm 17$ years, $81 \%$ were male. Overall $56 \%$ patients had penetrating mechanism, location of major injury was thorax in 48 , and $71 \%$ had signs of life (SOL) on arrival. The overall survival rate was $9.6 \%$. From 2010-2014 ERT utilization has decreased from $331 / 100000$ to $243 / 100$ 000 trauma admissions $(p=0.002)$ and the survival rate has improved from $7.9 \%$ to $11.3 \%$ ( $p<0.001)$. On regression, the independent predictors of survival were penetrating mechanism, age $<60$ years, SOL on arrival, no prehospital CPR and ISS. No patient aged $>60$ years with a blunt mechanism of injury (MOI) survived, and there were no survivors above the age of 70 years, regardless of injury mechanism.

Discussion Utilization of ERT has been decreased during the study period along with improved survival rates. The results of our study demonstrate that performing ERT on patients aged $>60$ years with a blunt $\mathrm{MOI}$ or on any patient aged $\geq 70$ years, regardless of $\mathrm{MOI}$, is futile and should be avoided.

Level of evidence Level III, prognostic studies.

\section{INTRODUCTION}

Trauma remains one of the leading causes of morbidity and mortality in USA. ${ }^{12}$ Both blunt and penetrating traumas can result in significant injuries that produce hemodynamic collapse refractory to initial, traditional resuscitative measures. During the past decades, emergency resuscitative thoracotomy (ERT) has been used in such circumstances as an urgent procedure to assist achieving homeostasis along with ongoing specific resuscitative maneuvers In addition, this invasive procedure has been evolving since its conception, from simple aortic artery occlusion to include pericardial decompression as well as open cardiac massage and repair. ${ }^{3}$ Beall et $a l^{5}$ were the first to formally describe the procedure nearly 50 years ago, however, it's role has not been well defined in trauma patients until recently. According to the Eastern Association for Surgery of Trauma, the strongest indication for ERT is to be used in patients who present pulseless to an emergency department (ED) with signs of life (SOL) after a penetrating thoracic injury. Other conditional indications include patients who present pulseless to an ED with SOL after a penetrating extrathoracic or blunt injury, as well as patients who present without SOL after a penetrating thoracic or extrathoracic injury or blunt injury. ${ }^{6}$ According to the Western Trauma Association (WTA), ERT is considered futile if prehospital cardiopulmonary resuscitation (CPR) exceeds 10 minutes after a blunt injury without a response, or if prehospital CPR exceeds 15 minutes after a penetrating trauma without a response. In addition, futility is likely when asystole is associated with no pericardial tamponade. ${ }^{7}$

ERT is a potentially life-saving procedure with long-term survival ranging from $10 \%$ to $30 \%$, depending on the mechanism of injury (MOI), that is, penetrating or blunt. ${ }^{8}$ Multiple independent predictors have been described for ERT, including the $\mathrm{MOI},{ }^{3}{ }^{10-12}$ anatomic location of major injury (LOMI), ${ }^{3}{ }^{13-15}$ prehospital CPR, ${ }^{14-16} \mathrm{SOL}$ on arrival to the ED, ${ }^{311} 13$ and the presence of vital signs. ${ }^{15} 1718$ Initial utilization of the focused assessment with sonography for trauma (FAST) may potentially avoid this futile intervention as the absence of cardiac motion or pericardial effusion on a FAST examination results in a zero survival rate. ${ }^{19}$ Although it may be able to identify patients with a survival potential, it does not necessarily predict survival in those ultimately undergoing ERT. Nonetheless, clinicians perform this procedure in an effort to expertly weigh the last chance of survival against the risk of rescuing patients with anoxic brain injury.

Trauma surgeons continue to be challenged by how best to clinically analyze exactly which subset of trauma patients with recoverable injuries may benefit from ERT. Therefore, the aim of our study was to analyze utilization and survival trends during 5 years as well as factors that influence survival after ERT. We hypothesized that there has been significant change in the utilization and survival trends during the 5-year period. 


\section{METHODS}

\section{Study design and population}

We conducted a 5-year (2010-2014) retrospective analysis of the American College of Surgeons (ACS) Trauma Quality Improvement Program (TQIP). We identified all adult patients who sustained trauma (age $\geq 18$ years) and underwent ERT, as defined by the International Classification of Disease-9th revision Clinical Modification procedure code 34.02. TQIP provides an opportunity for peer trauma centers to compare their processes of care-adjusted and risk-adjusted outcomes. As of 2014, it includes 721 hospitals (ie, 237 level-I, 259 level-II, 189 level-III/level-IV trauma centers, and 36 level-I/level-II pediatric-only centers). Trained abstractors record more than 100 variables concerning both the patient and the institution, including patient demographics; comorbid conditions; type and MOI; injury severity; prehospital and ED physiologic variables; in-hospital procedures and complications; and, outcome information that includes in-hospital mortality and discharge disposition. Intensive training mechanisms for the abstractors as well as inter-rater reliability audits of the participating sites ensures the reliability of the data. Institutional review board approval was not required for this study because the TQIP database contains only deidentified data. Although the ACS administers the program, the authors of this study are solely responsible for the analyses and conclusions presented here.

\section{Inclusion and exclusion criteria}

We included all trauma patients aged $\geq 18$ years who underwent ERT within 1 hour of arrival to ED. We excluded all trauma patients who sustained gunshot wound (GSW) to the head.

\section{Data points}

We retrieved the following data points from the TQIP: demographics (age, gender, race, and ethnicity); vitals on presentation (heart rate, systolic blood pressure (SBP), and temperature); Injury Severity Score (ISS); Abbreviated Injury Scale (AIS); hospital length of stay; MOI-blunt and penetrating, including GSWs and stab wounds (SWs); physiologic data from the scene of injury via emergency medical service (EMS) and on arrival to the ED; Glasgow Coma Scale; SOL; prehospital CPR and survival rate. 'Signs of life' were defined as organised electrocardiogram (EKG) activity, multiple pupillary responses, spontaneous respiratory attempts or movement, or unassisted blood pressure. Prehospital CPR was defined as a sudden, abrupt loss of cardiac function which occurs outside of the hospital, prior to admission at the center in which the registry is maintained, that results in loss of consciousness requiring the initiation of any component of basic and/or advanced cardiac life support by a healthcare provider.

\section{Outcomes measures}

The primary outcome was in-hospital survival. Secondary outcomes included survival to operating room, survival to intensive care unit, survival based on age, MOI and penetrating MOI (GSW and SW).

\section{Data analysis}

Missing data were treated as missing at random. Multiple imputations were performed using a missing value analysis technique to account for the missing values. This technique is used to reduce bias and increase the number of patients available. To impute the data sets, the original data set was analyzed for random missing data points using Little's missing completely at random test. We used the Markov chain Monte Carlo method for multiple imputations, that is, a collection of methods for simulating random draws from non-standard distributions. The following categories had missing data on heart rate, SBP, and temperature. Overall $<2 \%$ data were missing. However, we performed rigorous statistical analysis to analyze the missing variables and control for any bias caused by these variables.

Data are reported as mean (with SD) for continuous parametric data, as median (with IQR) for non-parametric data, and as proportion for categorical data. We used the Mann-Whitney $\mathrm{U}$ test and Student's t-test to explore differences in the two groups concerning non-parametric and parametric continuous variables, respectively. We used the $\chi^{2}$ test to identify differences in categorical variables between the two groups. Subanalysis was performed based on age as well as penetrating MOI. To assess the association between each variable and the binary outcomes, we performed a univariate analysis. Variables with a significant $(p<0.2)$ association on the univariate analysis were then used in a multivariate logistic regression model. On the multivariate logistic regression analysis, variables were considered significant at $p<0.05$. The model fit was assessed by the Hosmer-Lemeshow test. In the logistic regression model, the Hosmer-Lemeshow test exceeded 0.05 and the tolerance was greater than 0.1 for all independent variables with a variance inflation factor of less than 10.0. To explore trends in outcomes for categorical variables, we used the Cochran-Armitage trend test with years as a covariate. For trends of outcomes of continuous data, we used a linear regression analysis with years as a covariate. For our study, a $\mathrm{p}<0.05$ was considered statistically significant. All statistical analyses were performed using SPSS (V.24, SPSS, Chicago, Illinois, USA).

\section{RESULTS}

A total of 2229 patients underwent ERT between 2010 and 2014. Table 1 demonstrates the demographics and physiologic parameters of the study population. Mean age was $37 \pm 17$ years, $81 \%$ were men, $42.3 \%$ were white, and $13.5 \%$ were Hispanics. On the scene, the SBP was $61.8 \pm 59 \mathrm{~mm} \mathrm{Hg}$, and $37.5 \%$ had a pulse less than 60 beats per minute (bpm). On arrival to ED, SBP was $73.4 \pm 58.2 \mathrm{~mm} \mathrm{Hg}$, and $30.3 \%$ of patients had a pulse less than $60 \mathrm{bpm}$. Of the patients, 71\% presented to ED with SOL, $36 \%$ of the patients presented to ED with CPR in progress, $24.5 \%$ of the patients died in ED, and $68.4 \%$ were disposed to operating room from ED. The overall survival rate was $9.6 \%$. The MOI was penetrating in $56.3 \%$ of patients, including 43.7\%\% GSWs and 9.1\% SWs. LOMI was an isolated thorax in $48.1 \%$ of patients, and $41.1 \%$ had multiple injuries. The median ISS was 27 (9-75), and thoracic-AIS was 3 (3-6). Overall, 66.4\% of patients had an ISS $\geq 16$. In our study, the overall survival rate was $9.6 \%$ (13.3\% penetrating and $4.4 \%$ blunt, $\mathrm{p}<0.001)$.

In general, the overall rate of ERT has decreased from $331 / 100000$ trauma admissions in 2010 to $243 / 100000$ in $2014(p=0.002)$. Likewise, the survival rate has improved from $7.9 \%$ in 2010 to $11.3 \%$ in 2014 ( $<<0.001)$. Clearly, the 5 -year trend shows that survival has increased over the years. Figure 1 demonstrates the trend of ERT utilization and survival during the 5 -year period.

Patients who survived were more likely to be younger $(p=0.002)$. They had a higher SBP at the scene of injury $(p=0.015)$ and in the ED $(p=0.01)$. They were more likely to sustain multiple injuries $(p=0.003)$ and, interestingly, had a higher ISS $(\mathrm{p}<0.001)$ compared with those who died. In addition, they were more likely to present with SOL to the ED 
Table 1 Demographics and physiologic parameters of the study population

\begin{tabular}{|c|c|}
\hline Characteristics & ED thoracotomy $(n=2229)$ \\
\hline Age, years $($ mean $\pm S D)$ & $37.1 \pm 16.8$ \\
\hline Men & $81.2(n=1811)$ \\
\hline \multicolumn{2}{|l|}{ Race, \% (n) } \\
\hline White & $42.3(943)$ \\
\hline African-American & $36.3(810)$ \\
\hline Others & $21.4(476)$ \\
\hline Hispanics & $13.5(300)$ \\
\hline \multicolumn{2}{|l|}{ Vital parameters } \\
\hline \multicolumn{2}{|l|}{ EMS } \\
\hline $\mathrm{SBP}, \mathrm{mm} \mathrm{Hg}(\mathrm{mean} \pm \mathrm{SD})$ & $61.8 \pm 59$ \\
\hline Heart rate, bpm $($ mean $\pm S D)$ & $73.6 \pm 57$ \\
\hline Sl, median (IQR) & $1(0.68-1.33)$ \\
\hline Pulse <60 bpm, \% (n) & $37.5(836)$ \\
\hline \multicolumn{2}{|l|}{ ED } \\
\hline $\mathrm{SBP}, \mathrm{mm} \mathrm{Hg}($ mean $\pm \mathrm{SD})$ & $73.4 \pm 58.2$ \\
\hline Heart rate, bpm $($ mean $\pm S D)$ & $84.1 \pm 54.3$ \\
\hline SI, median (IQR) & $1(0.68-1.37)$ \\
\hline Pulse <60 bpm, \% (n) & $30.3(676)$ \\
\hline SOL, \% (n) & $81.4(1814)$ \\
\hline Prehospital CPR & $36 \%(802)$ \\
\hline \multicolumn{2}{|l|}{ ED disposition, \% (n) } \\
\hline Died & $24.5(547)$ \\
\hline Operating room & $68.4(1525)$ \\
\hline \multicolumn{2}{|l|}{ Injury parameters, } \\
\hline \multicolumn{2}{|l|}{ Mechanism of injury, \% (n) } \\
\hline Penetrating & $56.3(n=1254)$ \\
\hline GSW & $43.7(n=975)$ \\
\hline Stab & $9.1(n=279)$ \\
\hline Blunt & $43.7(n=975)$ \\
\hline \multicolumn{2}{|l|}{ LOMI, \% (n) } \\
\hline Isolated thorax & $48.2(1074)$ \\
\hline Isolated abdominal & $10.7(239)$ \\
\hline Multiple injuries & 41.1 (916) \\
\hline \multicolumn{2}{|l|}{ Injury severity and pattern } \\
\hline ISS, median (IQR) & $27(9-75)$ \\
\hline ISS $\geq 16, \%$ (n) & $66.4(1481)$ \\
\hline Thoracic-AIS, median (IQR) & $3(3-6)$ \\
\hline Abdominal-AIS, median (IQR) & $3(3-5)$ \\
\hline Head-AIS, median (IQR) & $3(3-5)$ \\
\hline Survival rate, $\%(n)$ & $9.6(213)$ \\
\hline
\end{tabular}

AIS, Abbreviated Injury Scale Score; bpm, beats per minute; CPR, cardiopulmonary resuscitation; ED, emergency department; EMS, emergency medical service; GSW, gunshot wound; ISS, Injury Severity Score; LOMI, location of major injury; SBP, systolic blood pressure; SI, Shock Index; SOL, signs of life.

$(\mathrm{p}<0.001)$, and were less likely to receive prehospital CPR $(\mathrm{p}<0.001)$. However, there was no difference in EMS transport time $(\mathrm{p}=0.28)$. Table 2 demonstrates the demographics and injury parameters between the survivors and the non-survivors.

Figure 2 demonstrates the subanalysis based on MOI and age. The highest rate of survival was seen in age groups 30-39 years and $40-49$ years. A significant decline in the survival rate was observed in patients $>50$ years of age undergoing ERT. No patient aged $>60$ years with a blunt mechanism survived

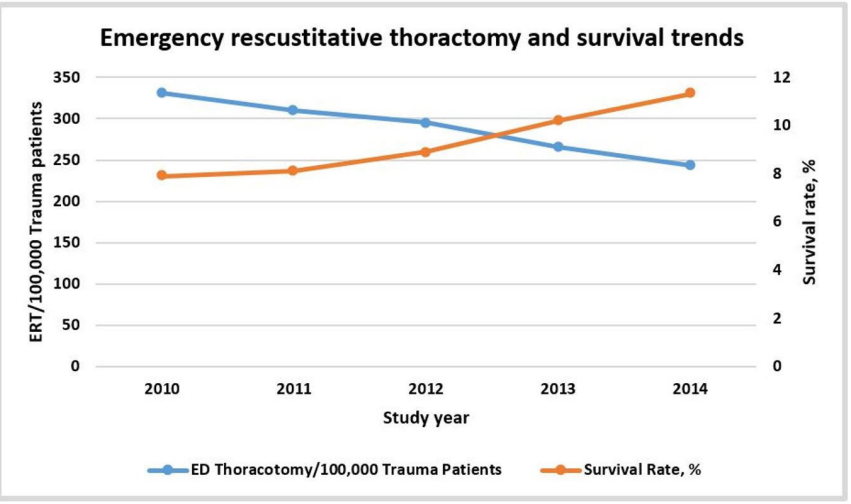

Figure 1 Trends of emergency resuscitative thoracotomy (ERT) utilization and survival during the 5-year study period. ED, emergency department.

and there was no survivor above the age of 70 years, regardless of MOI. The survival rate was highest for SWs compared with GSWs ( $30 \%$ vs $10.35, \mathrm{p}<0.001)$. Table 3 demonstrates the subanalysis based on the type of penetrating injury. The survival rate was higher for SWs of those aged 18-49 years. Interestingly, the survival rate was higher for the age group 60-69 years with GSWs compared with SWs (for which the survival rate was 0\%).

Table 4 Demonstrates the multivariate regression analysis for survival. After controlling for confounders including body region AIS (chest AIS, abdomen AIS and spine AIS), independent predictors of survival were age $<60$ (OR 2.7 (1.9-3.8)) years, penetrating MOI (OR 4.7 (2.9-7.6)), prehospital CPR (OR 0.76 (0.67-0.82)), and SOL on ED arrival (OR 1.9 (1.4-2.6)). Other independent predictors were ISS, ED SBP and ED heart rate $>60 \mathrm{bpm}$.

\section{DISCUSSION}

ERT is considered one of the most aggressive forms of resuscitation in trauma patients, and its role in trauma is still evolving. To the best of our knowledge, this is the largest nationwide study performed to analyze the role of ERT in the resuscitation of trauma patients. Our study demonstrates significant survival rates of both penetrating mechanism and blunt mechanism. It further suggests that an ERT is futile in patients with age $\geq 70$ years, regardless of the MOI as well as in those with age $\geq 60$ years with a blunt MOI. In addition, a penetrating MOI is the strongest predictor of survival after an ERT, with penetrating SWs resulting in the greatest survival rate.

Our analysis shows that from 2010 to 2014, the overall ERT rate has declined, and the survival rate has improved. This finding might be due to improvement in the quality of prehospital EMS, along with the development of specific ERT guidelines. In addition, better selection of a suitable patient population through the use of FAST for evaluating cardiac activity might have further decreased the total number of unnecessary ERTs. In our study, the overall survival rate was higher for a penetrating MOI compared with a blunt MOI. A WTA report based on a review of results for the total population had similar results. It reported a survival rate of $11.2 \%$ after a penetrating mechanism and $1.6 \%$ after a blunt mechanism. ${ }^{9}$ Though the results are similar, the survival rate was higher in both the penetrating and blunt groups in our analysis compared with the WTA report.

The benefit of ERT depends on the time between the loss of pulses and the procedure. According to WTA, performing ERT is futile in patients with cardiac arrest and ongoing CPR more than 
Table 2 Demographics information and injury characteristics of patients who survived or died

\begin{tabular}{|c|c|c|c|}
\hline Characteristics & $\begin{array}{l}\text { Survived } \\
(n=213)\end{array}$ & $\begin{array}{l}\text { Died } \\
(n=2016)\end{array}$ & $P$ values \\
\hline Age, years $($ mean $\pm S D)$ & $33.7 \pm 12.8$ & $37.4 \pm 17.1$ & 0.002 \\
\hline M & $81.7(174)$ & $81.2(1637)$ & 0.144 \\
\hline \multicolumn{4}{|l|}{ Race, \% (n) } \\
\hline White & $40.4(86)$ & $42.5(857)$ & 0.169 \\
\hline African-American & 34.7 (74) & $36.5(736)$ & \\
\hline Others & $24.8(53)$ & $20.9(423)$ & \\
\hline Hispanics & $16.4(35)$ & $13.1(265)$ & 0.18 \\
\hline \multicolumn{4}{|l|}{ Vital parameters } \\
\hline \multicolumn{4}{|l|}{ EMS } \\
\hline $\mathrm{SBP}, \mathrm{mm} \mathrm{Hg}\left(\mathrm{mean}_{ \pm} \mathrm{SD}\right)$ & $71.3 \pm 55.9$ & $60.8 \pm 59.6$ & 0.015 \\
\hline Heart rate, bpm (mean \pm SD) & $78.5 \pm 55.9$ & $73.1 \pm 57.1$ & 0.18 \\
\hline Pulse $<60$ bpm, \% (n) & $33.3(71)$ & $38.1(769)$ & 0.19 \\
\hline \multicolumn{4}{|l|}{ ED } \\
\hline $\mathrm{SBP}, \mathrm{mm} \mathrm{Hg}($ mean $\pm \mathrm{SD})$ & $83.2 \pm 52$ & $72.4 \pm 58$ & 0.01 \\
\hline Heart rate, bpm (mean \pm SD) & $101.79 \pm 46.8$ & $82.3 \pm 54.7$ & $<0.001$ \\
\hline Pulse <60 bpm, \% (n) & $17.3(37)$ & $31.7(641)$ & $<0.001$ \\
\hline \multicolumn{4}{|l|}{ Mechanism of injury, \% (n) } \\
\hline Penetrating & $84(179)$ & $53.3(1075)$ & $<0.001$ \\
\hline GSW & $56.4(101)$ & $81.4(874)$ & \\
\hline Stab & $43.6(78)$ & $18.6(201)$ & \\
\hline Blunt & $16(34)$ & $46.7(941)$ & \\
\hline \multicolumn{4}{|l|}{ LOMI, \% (n) } \\
\hline Isolated thorax & 37.1 (79) & 49.5 (995) & 0.003 \\
\hline Isolated abdominal & $12.2(26)$ & $10.5(213)$ & \\
\hline Multiple injuries & $50.7(108)$ & $40.0(808)$ & \\
\hline \multicolumn{4}{|l|}{ Injury severity and pattern } \\
\hline ISS, median (IQR) & $25(10-58)$ & $22(10-41)$ & $<0.001$ \\
\hline ISS $\geq 16, \%$ (n) & $63.9(135)$ & $66.7(1346)$ & 0.32 \\
\hline Thoracic-AIS, median (IQR) & $4(3-6)$ & $3(3-6)$ & 0.63 \\
\hline Abdominal-AIS, median (IQR) & $3(3-5)$ & $3(3-5)$ & 0.25 \\
\hline Neck-AIS, median (IQR) & $3(3-5)$ & $3(3-5)$ & 0.15 \\
\hline $\mathrm{SOL}, \%(\mathrm{n})$ & $92.0(196)$ & $80.3(1620)$ & $<0.001$ \\
\hline Prehospital CPR & $25.4(54)$ & $37.1(748)$ & $<0.001$ \\
\hline \multicolumn{4}{|l|}{ ED disposition, \% (n) } \\
\hline Died & $1.9(4)$ & $26.9(544)$ & $<0.001$ \\
\hline Operating room & $86.9(185)$ & $66.5(1340)$ & \\
\hline
\end{tabular}

AIS, Abbreviated Injury Scale Score; bpm, beats per minute; CPR, cardiopulmonary resuscitation; ED, emergency department; EMS, emergency medical service; GSW, gunshot wound; ISS, Injury Severity Score; LOMI, location of major injury; SBP, systolic blood pressure; SI, Shock Index; SOL, signs of life.

10 minutes in blunt injury and 15 minutes in penetrating injury. ${ }^{7}$ In addition, several studies have demonstrated a dismal survival prognosis in patients with cardiac arrest at the scene and undergoing prehospital CPR. ${ }^{20} 21$ In our analysis, only 54 (25.4\%) of the patients who survived ERT underwent prehospital CPR. It signifies that patients who lost pulse either in-hospital or shortly before arrival to the ED had the highest survival. Similar results have been reported by other small studies. Moore $e t a l^{7}$ studied 56 patients who survived ERT of which only 19 (33.9\%) underwent prehospital CPR . Similarly, Powell et al 22 analyzed 959 patients who underwent ERT of which 62 survived, more than half of which did not require prehospital CPR.

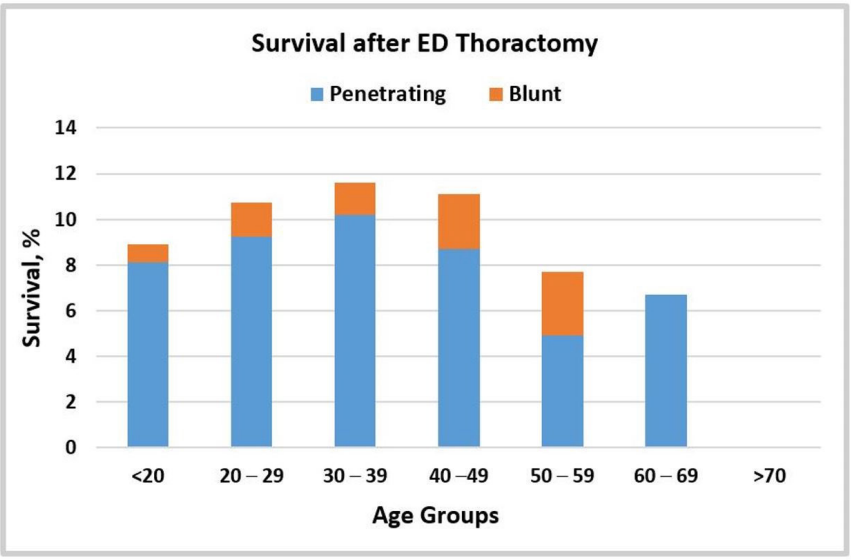

Figure 2 Survival after emergency department (ED) thoracotomy based on age and mechanism of injury. Age groups in years.

Our study is also the first to report survival rates based on age groups after ERT. The highest survival rate was seen in ages 20-49 years. An ERT was futile in all patients age $\geq 70$ years, regardless of MOI as well as in patients over the age of 60 years with a blunt trauma. Additionally, for patients with penetrating injuries, the survival rate was highest for those with SWs compared with GSWs for the age group 20-49 years. A review by Rhee $e t a^{3}$ analyzed 24 ERT publications during 25 years, and they also reported similar results. The survival rate in their review was $16.8 \%$ for SWs and $4.3 \%$ for GSWs, much less than what was observed in our study. This difference might be due to the increasing selection of appropriate patients, which would reflect improved survival during the years. Similarly, Tyburski et $a^{23}$ analyzed a total of 152 patients with a penetrating injury to the heart who underwent ERT. They reported a total survival rate of $8 \%$. This survival rate was attributed to SWs to the heart as none of the patients who had GSWs survived. Interestingly, for the age group 60-69 years, the survival rate was 37\% for GSWs and $0 \%$ for SWs.

Numerous other studies of ERT have been reported in the literature in the past two decades. Most of them have been reported from a single institution and are limited by the small number of patients undergoing ERT. Our nationwide analysis is the first one to report on ERTs in such a large population. The assessment of physiological parameters at arrival were correlated with survival. The presence of SBP, heart rate more than $60 \mathrm{bpm}$, a penetrating mechanism, prehospital CPR, and SOL were the independent predictors of survival. Similar results have been reported in the literature. ${ }^{32}$ Interestingly, one of the two most

Table 3 Subanalysis based on the type of penetrating injury

\begin{tabular}{llclc}
\hline & $\begin{array}{l}\text { Survival } \\
(\mathrm{n}=179)\end{array}$ & $\begin{array}{l}\text { Gunshot } \\
\text { wound, } \\
(\mathrm{n}=975)\end{array}$ & $\begin{array}{l}\text { Stab wound, } \\
(\mathrm{n}=279)\end{array}$ & P values \\
\hline Age groups & $12.4 \%(21)$ & $8.3 \%(12)$ & $25.8 \%(8)$ & 0.006 \\
\hline$<20,(\mathrm{n}=175)$ & $13.5 \%(68)$ & $8.8 \%(35)$ & $31.1 \%(33)$ & $<0.001$ \\
\hline $20-29,(\mathrm{n}=502)$ & $15.4 \%(39)$ & $11.9 \%(23)$ & $26.2 \%(16)$ & 0.007 \\
\hline $30-39,(\mathrm{n}=254)$ & $16.9 \%(29)$ & $11.4 \%(14)$ & $30.6 \%(15)$ & 0.002 \\
\hline $40-49,(\mathrm{n}=172)$ & $11.2 \%(12)$ & $8.2 \%(6)$ & $17.6 \%(6)$ & 0.15 \\
\hline $50-59,(\mathrm{n}=107)$ & $34.5 \%(10)$ & $37.0 \%(10)$ & $0(0)$ & $<0.001$ \\
\hline $60-69,(\mathrm{n}=29)$ & $0 \%(0)$ & $0 \%(0)$ & $0 \%(0)$ & $\mathrm{N} / \mathrm{A}$ \\
\hline$\geq 70,(n=16)$ & & & & \\
\hline
\end{tabular}

Age groups in years.

$\mathrm{N} / \mathrm{A}$, not applicable. 


\begin{tabular}{|c|c|c|c|}
\hline Covariates & OR & $95 \% \mathrm{Cl}$ & $P$ values \\
\hline Age $<60$ years & 2.70 & 1.95 to 3.83 & $<0.001$ \\
\hline ISS & 1.1 & 1.01 to 1.21 & 0.03 \\
\hline ED SBP $(m m ~ H g)$ & 1.09 & 1.05 to 1.11 & 0.01 \\
\hline ED heart rate $>60 \mathrm{bpm}$ & 1.29 & 1.14 to 1.31 & 0.02 \\
\hline Penetrating mechanism of injury & 4.76 & 2.97 to 7.60 & $<0.001$ \\
\hline Prehospital CPR & 0.76 & 0.67 to 0.82 & 0.002 \\
\hline SOL on ED arrival & 1.96 & 1.46 to 2.63 & 0.015 \\
\hline
\end{tabular}

bpm, beats per minute; CPR, cardiopulmonary resuscitation; ED, emergency

department; ISS, Injury Severity Score; SBP, systolic blood pressure; SOL, signs of life

significant predictors of survival which has previously not been described in the literature is age $<60$ years. Theoretically, when compared with adults, elderly patients have a decreased physiologic reserve. Thus, an injury that completely overcomes their physiologic reserves is almost certainly not survivable.

An emerging alternative resuscitative measure to ERT that is gaining interest is resuscitative endovascular balloon occlusion of the aorta (REBOA). It is selectively used in patients with exsanguinating hemorrhage below the diaphragm. REBOA is still a novel resuscitative tool, and its use remains controversial. Joseph et al ${ }^{25}$ reviewed 87 autopsy reports of patients who underwent ERT to measure the potential benefit of REBOA in such a patient population. They concluded that REBOA would have been beneficial in only $49 \%$ of the patients undergoing ERT, mostly in about $50 \%$ of patients with blunt thoracic injuries. Teeter $e t a l^{26}$ compared REBOA with ERT and concluded that the length of cardiac compressions is longer for patients receiving REBOA before, during, and after aortic occlusion compared with ERT. Although non-significant, a multi-institutional trial has also demonstrated that the time from admission to aortic occlusion is higher for open aortic occlusion compared with REBOA. The time required to perform the thoracotomy may be better spent performing closed cardiac compressions concurrently with REBOA, as that lost time significantly reduces the length of time of cardiac compression, and possibly cerebral and coronary perfusion. ${ }^{27}$

Another major concern regarding ERT is the safety of the provider. Several studies have demonstrated that trauma victims may be carriers of bloodborne pathogens, which is a major concern for healthcare providers performing ERT. ${ }^{28}$ Appropriate precautions should be taken before performing this heroic procedure, including double glove, protective eye gear, and integrating the risk of incidents due to fractured ribs in the team briefing.

Several limitations exist in this analysis. TQIP does not capture all trauma patients in USA. Our results may not be generalizable given the retrospective nature of the database. In addition, it lacks data such as cardiac activity or pericardial effusion on FAST, neurological recovery, organ donation information, and precise time to procedure. We do not have data regarding the procedures performed after ERT, however, in regression analysis we controlled for injury severities. Moreover, there is addition of new centers during the later years of TQIP which could skew the results. Finally, we were not able to analyze the exact cause of the decreased utilization in our study. This decrease might be explained by the newly evolving resuscitative procedures such as endovascular occlusion of the aorta, however, the 2010-2014 TQIP data set doesn't provide patients who underwent this procedure. Nevertheless, this is the largest and only nationwide description of ERT, and reasonable conclusions can be drawn regarding universal survival after ERT in adult populations.

\section{Conclusions}

Utilization of ERT has been decreased during the study period along with improved survival rates. Evolving endovascular resuscitative techniques and appropriate patient selection may have a role in the observed results. Additionally, the results of our study demonstrate that performing ERT on patients aged $>60$ years with a blunt $\mathrm{MOI}$ or on any patient aged $\geq 70$ years, regardless of MOI, is futile and should be avoided. More studies are required to further define the appropriate patient population that can benefit from this invasive procedure.

Contributors BJ, MK, FJ, RL and PR designed this study, searched the literature and collected the data. BJ, MK, FJ and PR analyzed the data. All authors participated in data interpretation, manuscript preparation and approval.

Funding The authors have not declared a specific grant for this research from any funding agency in the public, commercial or not-for-profit sectors.

Competing interests None declared.

Patient consent Not required.

Provenance and peer review Not commissioned; externally peer reviewed.

Open access This is an open access article distributed in accordance with the Creative Commons Attribution Non Commercial (CC BY-NC 4.0) license, which permits others to distribute, remix, adapt, build upon this work non-commercially, and license their derivative works on different terms, provided the original work is properly cited, appropriate credit is given, any changes made indicated, and the use is non-commercial. See: http://creativecommons.org/licenses/by-nc/4.0/

\section{REFERENCES}

1. Prevention CfDCa. FastStats - leading causes of death: Centers for Disease Control and Prevention, 2017.

2. Rhee P, Joseph B, Pandit V, Aziz H, Vercruysse G, Kulvatunyou N, Friese RS. Increasing trauma deaths in the United States. Ann Surg 2014;260:13-21.

3. Rhee PM, Acosta J, Bridgeman A, Wang D, Jordan M, Rich N. Survival after emergency department thoracotomy: review of published data from the past 25 years. J Am Coll Surg 2000;190:288-98

4. Hopson LR, Hirsh E, Delgado J, Domeier RM, Krohmer J, McSwain NE, Weldon C, Friel M, Hoyt DB. National Association of EMS Physicians Standards and Clinical Practice Committee. Guidelines for withholding or termination of resuscitation in prehospital traumatic cardiopulmonary arrest. J Am Coll Surg 2003;196:475-81.

5. Beall AC, Diethrich EB, Crawford HW, Cooley DA, De Bakey ME. Surgical management of penetrating cardiac injuries. Am J Surg 1966;112:686-92.

6. Seamon MJ, Haut ER, Van Arendonk K, Barbosa RR, Chiu WC, Dente CJ, Fox N, Jawa RS, Khwaja K, Lee JK, et al. An evidence-based approach to patient selection for emergency department thoracotomy: a practice management guideline from the Eastern Association for the Surgery of Trauma. J Trauma Acute Care Surg 2015;79:159-73

7. Moore EE, Knudson MM, Burlew CC, Inaba K, Dicker RA, Biffl WL, Malhotra AK, Schreiber MA, Browder TD, Coimbra R, et al. Defining the limits of resuscitative emergency department thoracotomy: a contemporary Western Trauma Association perspective. J Trauma 2011;70:334-9.

8. Cothren CC, Moore EE. Emergency department thoracotomy for the critically injured patient: Objectives, indications, and outcomes. World J Emerg Surg 2006;1:4.

9. Working Group, Ad Hoc Subcommittee on Outcomes, American College of Surgeons, Committee on Trauma. Practice management guidelines for emergency department thoracotomy. Working Group, Ad Hoc Subcommittee on Outcomes, American College of Surgeons-Committee on Trauma. J Am Coll Surg 2001;193:303.

10. Velmahos GC, Degiannis E, Souter I, Allwood AC, Saadia R. Outcome of a strict policy on emergency department thoracotomies. Arch Surg 1995;130:774-7.

11. Morrison JJ, Poon H, Rasmussen TE, Khan MA, Midwinter MJ, Blackbourne LH, Garner JP. Resuscitative thoracotomy following wartime injury. J Trauma Acute Care Surg 2013;74:825-9.

12. Capote A, Michael A, Almodovar J, Chan P, Skinner R, Martin M. Emergency department thoracotomy: too little, too much, or too late. Am Surg 2013;79:982-6.

13. Easter JS, Vinton DT, Haukoos JS. Emergent pediatric thoracotomy following traumatic arrest. Resuscitation 2012;83:1521-4.

14. Lustenberger $T$, Labler L, Stover JF, Keel MJ. Resuscitative emergency thoracotomy in a Swiss trauma centre. Br J Surg 2012;99:541-8.

15. Johannesdottir BK, Mogensen B, Gudbjartsson T. Emergency thoracotomy as a rescue treatment for trauma patients in Iceland. Injury 2013;44:1186-90. 
16. Edens JW, Beekley AC, Chung KK, Cox ED, Eastridge BJ, Holcomb JB, Blackbourne LH. Longterm outcomes after combat casualty emergency department thoracotomy. J Am Coll Surg 2009;209:188-97.

17. Schnüriger B, Inaba K, Branco BC, Salim A, Russell K, Lam L, Plurad D, Demetriades D. Organ donation: an important outcome after resuscitative thoracotomy. J Am Coll Surg 2010;211:450-5.

18. Gomez G, Fecher A, Joy T, Pardo I, Jacobson L, Kemp H. Optimizing outcomes in emergency room thoracotomy: a 20-year experience in an urban Level I trauma center. Am Surg 2010;76:406-10.

19. Inaba K, Chouliaras K, Zakaluzny S, Swadron S, Mailhot T, Seif D, Teixeira P, Sivrikoz E, Ives $C$, Barmparas G, et al. FAST ultrasound examination as a predictor of outcomes after resuscitative thoracotomy: a prospective evaluation. Ann Surg 2015;262:512-8

20. Martin SK, Shatney CH, Sherck JP, Ho CC, Homan SJ, Neff J, Moore EE. Blunt trauma patients with prehospital pulseless electrical activity (PEA): poor ending assured. J Trauma 2002;53:876-81.

21. Rabinovici R, Bugaev N. Resuscitative thoracotomy: an update. Scand J Surg 2014;103:112-9.

22. Powell DW, Moore EE, Cothren CC, Ciesla DJ, Burch JM, Moore JB, Johnson JL. Is emergency department resuscitative thoracotomy futile care for the critically injured patient requiring prehospital cardiopulmonary resuscitation? J Am Coll Surg 2004;199:211-5.
23. Tyburski JG, Astra L, Wilson RF, Dente C, Steffes C. Factors affecting prognosis with penetrating wounds of the heart. J Trauma 2000;48:587-91.

24. Asensio JA, Murray J, Demetriades D, Berne J, Cornwell E, Velmahos G, Gomez H, Berne TV. Penetrating cardiac injuries: a prospective study of variables predicting outcomes. J Am Coll Surg 1998;186:24-34.

25. Joseph B, Ibraheem K, Haider AA, Kulvatunyou N, Tang A, O'Keeffe T, Bauman ZM, Green DJ, Latifi R, Rhee P. Identifying potential utility of resuscitative endovascular balloon occlusion of the aorta: An autopsy study. J Trauma Acute Care Surg 2016;81(Suppl 2):S128-S132.

26. Teeter W, Romagnoli A, Hoehn M, Menaker J, Hu P, Stein D, Scalea T, Brenner M 303 Resuscitative endovascular balloon occlusion of the aorta improves quality of resuscitation versus thoracotomy in patients in traumatic arrest. Ann Emerg Med 2016:68:S117.

27. DuBose JJ, Scalea TM, Brenner M, Skiada D, Inaba K, Cannon J, Moore L, Holcomb J, Turay D, Arbabi CN, et al. The AAST prospective Aortic Occlusion for Resuscitation in Trauma and Acute Care Surgery (AORTA) registry: data on contemporary utilization and outcomes of aortic occlusion and resuscitative balloon occlusion of the aorta (REBOA). J Trauma Acute Care Surg 2016;81:409-19.

28. Sloan EP, McGill BA, Zalenski R, Tsui P, Chen EH, Duda J, Morris M, Sherer R, Barrett J. Human immunodeficiency virus and hepatitis $B$ virus seroprevalence in an urban trauma population. J Trauma 1995;38:736-41. 